\title{
Enhanced expression of a cloned and sequenced Ciona intestinalis TNF $\alpha$-like (CiTNF $\alpha$ ) gene during the LPS-induced inflammatory response
}

\author{
Nicolò Parrinello • Aiti Vizzini • Vincenzo Arizza • \\ Giuseppina Salerno • Daniela Parrinello • \\ Matteo Cammarata • Francesca Tiziana Giaramita • \\ Mirella Vazzana
}

Received: 21 April 2008 /Accepted: 4 September 2008 / Published online: 21 October 2008

(C) Springer-Verlag 2008

\begin{abstract}
A tumor necrosis factor-alpha (TNF $\alpha)$-like gene from Ciona intestinalis (CiTNF $\alpha$-like) body wall challenged with bacterial lipopolysaccharide (LPS) was cloned and sequenced $4 \mathrm{~h}$ after LPS inoculation. An open reading frame of $936 \mathrm{bp}$ encoding a propeptide of 312 amino acids $(35.4 \mathrm{kDa})$ displaying a transmembrane domain from positions 7 to 29, a TACE cleavage site, and a mature peptide domain of 185 amino acids $(20.9 \mathrm{kDa})$, was determined with a predicted isoelectric point of 9.4. The phylogenetic tree based on deduced amino acid sequences of invertebrate TNF-like protein and vertebrate TNFs supported the divergence between the ascidian and vertebrate TNF families, whereas D. melanogaster Eiger A and B TNF-like sequences were distinctly separated from the chordate TNFs. Thus, the ascidian TNF $\alpha$-like cytokine was upregulated by in vivo LPS challenge supporting its proinflammatory role. In the pharynx, increased expression levels were found following analysis by real-time polymerase chain reaction, whereas in situ hybridization assay showed positive hemocytes both in the tissue and in circulating hemocytes. Finally, Western blot with monoclonal antibodies disclosed human TNF $\alpha$ epitopes in a $15-\mathrm{kDa}$ protein component of the hemolymph serum and in a 43$\mathrm{kDa}$ protein contained in the hemocyte lysate supernatant
\end{abstract}

This work was supported by a research grant from the Italian Ministry of University and Scientific Research (PRIN 2006 to N. Parrinello), co-funded by the University of Palermo.

N. Parrinello $(\square) \cdot$ A. Vizzini $\cdot$ V. Arizza $\cdot$ G. Salerno

D. Parrinello $\cdot$ M. Cammarata $\cdot$ F. T. Giaramita $\cdot$ M. Vazzana

Dipartimento di Biologia Animale,

Laboratory of Marine Immunobiology, Università di Palermo,

Via Archirafi 18,

90123 Palermo, Italy

e-mail: nicpar@unipa.it prepared in the presence of detergents. Both soluble and hemocyte-bound CiTNF $\alpha$-like protein therefore appeared to be modulated by the LPS challenge.

Keywords TNF $\alpha \cdot$ CiTNF $\alpha$-like .

CiTNF $\alpha$-like expression · Inflammatory response · Pharynx · Hemocytes · Ciona intestinalis (Tunicata)

\section{Introduction}

In vertebrates, tumor necrosis factor-alpha $(\mathrm{TNF} \alpha)$ is a component of a large TNF family characterized by the conserved TNF signature sequence; it is a type II transmembrane protein with an extracellular homotrimeric C-terminal TNF homology domain characterized by several conserved features (Magor and Magor 2001; Bodmer et al. 2002). In mammals, TNF $\alpha$ is a pleiotropic and multifunctional cytokine playing a pivotal role in innate immune response and in cell proliferation, differentiation, apoptosis, and the stimulation of the synthesis of collagen in wound healing and tissue repair (Goetz et al. 2004; Idriss and Naismith 2000). Following stimulation by bacterial lipopolysaccharide (LPS), a membrane-bound form is cleaved, and mature $\mathrm{TNF} \alpha$ is released as soluble form by a variety of cell types, including macrophages, monocytes, granulocytes, and NK-cells, and regulates inflammatory reactions by interacting with other pro-inflammatory cytokines, e.g., interleukin-1 (IL-1) and IL-6 (Akira et al. 1990). In fish, $\mathrm{TNF} \alpha$ recruits and activates inflammatory cells (Goetz et al. 2004; Ordás et al. 2007; Praveen et al. 2006).

In the invertebrate immune system, cell proliferation, phagocytosis, and chemotaxis appear to be regulated by 
cytophilic humoral molecules with functional similarities to vertebrate cytokines (Beck 1998; Beschin et al. 2003), being capable of modulating defence responses to exogenous and endogenous insults. Invertebrate TNF-like molecules have primarily been derived from indirect studies by using antibodies against mammalian TNF $\alpha$ (Beshin et al. 2001). The analogy is also based on the sensitivity of invertebrate immunocytes to the effects of vertebrate cytokines, and the responsiveness of vertebrate immune cells to invertebrate factors. Epitopes recognized by antibodies against heterologous cytokine have been found in sponges (Pfeifer et al. 1992) and molluscs (Ouwe-MissiOukem-Boyer et al. 1994); in the mollusc Mytilus edulis, $\mathrm{TNF} \alpha$-like gene expression is involved in immune-neural communication (Hughes et al. 1990), and a homolog of TNF $\alpha$ affects cell signaling and function in the hemocytes of M. galloprovincialis (Betti et al. 2006). TNF $\alpha$-like molecules and activity have been described in insect hemocytes (Franchini et al. 1996; Wittwer et al. 1999). Recently, isoforms of a type II transmembrane protein with a C-terminal TNF homology domain (Eiger) expressed in Drosophila melanogaster have been cloned and sequenced (Moreno et al. 2002) and appear to act as inducers of apoptosis. Finally, despite the absence of any gene homology, an earthworm coelomic fluid cytotoxic factor (CCF-1) has shown low sequence similarity and functional analogy with mammal TNF (Olivares Fontt et al. 2002; Bilej et al. 2006).

Tunicates are regarded as a key group in chordate phylogenesis (Hori and Osawa 1987; Field et al. 1988; Zeng and Swalla 2005; Swalla et al. 2000) and have recently been proposed as the sister group of vertebrates (Delsuc et al. 2006). The debate regarding chordate phylogenetic relationships has further enhanced interest in considerations of ascidians (a class of tunicates) as an unique experimental system for evolutionary immunological studies on the emergence of vertebrate immunity. Hemocytes are protagonists of ascidian immunity (Parrinello 1996; Pinto et al. 2003; Parrinello et al. 2007; Vizzini et al. 2008; Shida et al. 2003; Ballarin et al. 2001), and ascidian cytokine-like molecules have been revealed by immunological (antibodies against heterologous cytokines) and biochemical methods. Humoral factors named "tunicate-cytokines" stimulate cell proliferation and modulate hemocyte phagocytosis activity or opsonized yeast (see Beschin et al. 2001; Parrinello et al. 2007). Recent progress in the genome sequencing of Ciona intestinalis has led to the development of an important tool for examining gene function and expression in immune responses. cDNA/EST derived from $C$. intestinalis hemocytes together with the identification of the corresponding gene in the draft Ciona genome sequence (Terajima et al. 2003; Shida et al. 2003) have demonstrated the existence of an ectodysplasin/TNF-like multigene family. Recently, the $C$. savigny genome has been sequenced, and a TNF-like gene predicted and annotated. However, whether ascidian cells and tissues express TNF in inflammatory reactions remains to be elucidated, and no data exist on cytokine involvement during their immune responses. Since previous papers have reported that, in the $C$. intestinalis body wall, an inflammatory reaction can be induced by injecting inflammatory agents (Parrinello et al. 1984a, b) including LPS (Parrinello et al. 2007; Vizzini et al. 2008), we have examined the early phase of this response to check for the involvement of a $\mathrm{TNF} \alpha$-like cytokine.

In the present paper, we report the cloning and sequencing of a CiTNF $\alpha$-like cDNA and, for the first time, demonstrate that LPS promptly induces the gene expression as shown by real-time polymerase chain reaction (PCR) analysis and in situ hybridization (ISH) assay. Comparative sequence analysis has revealed that the cloned $C$. intestinalis and the predicted $C$. savigny TNF-like genes cluster at a phylogenetic position close to vertebrate TNFs, whereas a considerable distance separates ascidian TNFs from $D$. melanogaster Eiger isoforms, with an even greater distance separating ascidian TNFs from earthworm CCF. Finally, monoclonal antibodies have identified epitopes of human recombinant TNF $\alpha$ $(\mathrm{hrTNF} \alpha)$ in a $15-\mathrm{kDa}$ protein of the hemolymph serum and in a 43-kDa protein of the hemocyte lysate supernatant, and both appear to be modulated by LPS challenge.

\section{Materials and methods}

\section{Tunicates}

Ascidians were collected from Termini Imerese harbor (Sicily, Italy), maintained in tanks with aerated sea water at $15^{\circ} \mathrm{C}$, and fed every second day with the marine invertebrate diet coraliquid (Sera Heinsberg, Germany).

\section{LPS injection}

LPS (Escherichia coli 055:B5; Sigma-Aldrich, Germany) solution was prepared in sterile marine solution (MS: $12 \mathrm{mM} \mathrm{CaCl} 2 \cdot 6 \mathrm{H}_{2} \mathrm{O}, 11 \mathrm{mM} \mathrm{KCl}, 26 \mathrm{mM} \mathrm{MgCl} 2 \cdot 6 \mathrm{H}_{2} \mathrm{O}$, $43 \mathrm{mM}$ TRIS-HCl, $0.4 \mathrm{M} \mathrm{NaCl}, \mathrm{pH} 8.0$; isosmotic with $C$. intestinalis hemolymph at $1090 \mathrm{mOsm} \mathrm{kg}{ }^{-1}$ ). The solution was inoculated (100 $\mu \mathrm{g}$ LPS in $100 \mu \mathrm{l} \mathrm{MS}$ per animal) into the tunic tissue at the median body wall region. Ascidians, both untreated and injected with MS $(100 \mu 1)$, were used as controls.

Hemolymph collection and preparation of hemocyte suspension

To collect hemocytes, hemolymph was harvested into a two-fold excess of ice-cold sterile anticoagulant solution 
(11 mM KCl, $43 \mathrm{mM}$ TRIS-HCl, 0.4 M NaCl, $10 \mathrm{mM}$ EDTA, pH 7.4). The hemolymph was withdrawn from the heart with a sterile syringe containing anticoagulant solution (1:2) and immediately centrifuged at $800 \mathrm{~g}$ $\left(10 \mathrm{~min}, 4^{\circ} \mathrm{C}\right)$. The hemocytes were washed with ice-cold sterile anticoagulant solution and suspended in MS (see above). Cells were counted by using an improved Neubauer chamber. Dead hemocytes were estimated by the Trypan blue $(0.05 \%$ final concentration in MS) exclusion test, and values lower than $2.0 \%$ were found.

To prepare serum, the hemolymph was allowed to stand for $1 \mathrm{~h}$ at room temperature and was then centrifuged at $800 \mathrm{~g}$ for $15 \mathrm{~min}$ at $4^{\circ} \mathrm{C}$.

\section{Hemocyte lysate preparation}

Hemocytes were suspended in RIPA buffer (50 mM TRIS$\mathrm{HCl}, \mathrm{pH} 7.4,150 \mathrm{mM} \mathrm{NaCl}, 0.1 \mathrm{mM}$ EDTA, 1\% Triton X$100,1 \%$ sodium deoxycholate, $0.1 \%$ SDS) with a protease inhibitor cocktail (pepstatin A, E-64, bestatin, leupeptin, aprotinin, and AEBSF) and incubated on ice for $20 \mathrm{~min}$. After incubation, they were shaken vigorously three times. Hemocyte lysates were centrifuged at $14,000 \mathrm{~g}$ for $20 \mathrm{~min}$ at $4{ }^{\circ} \mathrm{C}$, and supernatants held at $-80{ }^{\circ} \mathrm{C}$.

Protein content was measured by the Bradford method (Bradford 1976) with bovine serum albumin (BSA) as a standard.

\section{Pharynx and body wall explants}

The tunic surface was cleaned and sterilized with ethyl alcohol, and pharynx fragments $(200 \mathrm{mg})$ were excised from the injection site at various times after inoculation (0-12 h). To prepare histological sections, body wall fragments containing both tunic and pharynx tissue were excised from the injection site.

\section{Total RNA extraction and cDNA synthesis}

To check for CiTNF $\alpha$ mRNA expression, pharynx (200 mg/ascidian) was explanted at various times (from 1 to $48 \mathrm{~h}$ ), immediately soaked in RNAlater Tissue collection (Ambion, Austin, Tex.), and stored at $-80^{\circ} \mathrm{C}$. Total RNA was isolated from the ascidian tissues by using an RNAqueous-Midi Kit purification system (Ambion) and reverse-transcribed by the Cloned AMV First-Strand cDNA Synthesis Kit (Invitrogen).

Database search and primer design

The amino acid sequence of human TNF $\alpha$ (accession number: NP 000585) was used for a BLAST search of a $C$. intestinalis genomic sequence database in the Ensemble genome browser, which produces and maintains automatic annotation of selected eukaryotic genomes. The following genes, which show sequence similarities with components of the TNF family, were identified (Ensemble ID: ENSCING00000008162 EN SCINP00000023425, ENSCINP00000016689, ENSCINP00000000806, ENSCINP00000026947). The ENSCING00000008162 predicted gene showed the highest similarity with vertebrate $\mathrm{TNF} \alpha$ (sequence alignments and comparative analysis). Two primer pairs were designed from the sequence flanking the $5^{\prime}$ and $3^{\prime}$ ends in order to obtain overlapping parts of the coding region (Table 1).

Cloning and sequencing of PCR products

The primer pairs were used for amplifying cDNA obtained by reverse-transcription of mRNA of pharynx fragments excised from the body wall injection site $4 \mathrm{~h}$ after LPS injection. PCR was performed with AmpliTaq Gold DNA Polymerase (Applied Biosystems) and the primers listed in Table 1. Amplification comprised $2 \mathrm{~min}$ of initial denaturation at $95^{\circ} \mathrm{C}$, followed by 30 cycles consisting of $95^{\circ} \mathrm{C}$ for $30 \mathrm{~s}, 1 \mathrm{~min}$ at the respective annealing temperatures, $72^{\circ} \mathrm{C}$ for $1 \mathrm{~min}$, and a final extension at $72^{\circ} \mathrm{C}$ for $7 \mathrm{~min}$. Finally, PCR products were cloned into the pCRIIvector (TA cloning Kit, Invitrogen) and sequenced. To determine the nucleotide sequence, suitable amounts of lyophilized samples were analyzed at the CRIBI Biotechnology Center of the University of Padua, Italy (http://bmr.cribi.unipd.it) on an ABI PRISM-DNA sequencer (Applied Biosystems).

Sequence and phylogenetic analysis

To examine deduced amino acid sequence homologies, multiple alignments were accomplished with the Clustal W program (Thompson et al. 1994). The sequence alignment was performed with Clustal X v.1.81 (Thompson et al. 1997) and similarity shaded with GeneDoc v.2.6.002 (Nicholas and Nicholas 1997). A phylogenetic tree was constructed by the neighbor-joining method (NJ), and 1000

Table 1 Primers used

\begin{tabular}{ll}
\hline Primer & Sequence \\
\hline $\begin{array}{l}\text { CiTNF1 forward } \\
\text { primer }\end{array}$ & 5'-GAC AGT ACT TGG TTT ACA TGC-3' \\
CiTNF1 reverse & $5^{\prime}$-AGA ACA TATA TAT GGA CGA TGC- \\
primer & $3^{\prime}$ \\
CiTNF2 forward & $5^{\prime}$-AAT ATG CAG TCC TTG TCG T-3' \\
primer & \\
CiTNF2 reverse & 5'-CCA TAT GTG TCA GCA TAC AA-3' \\
primer & \\
\hline
\end{tabular}


bootstrap replicates were performed. With the exception of C. savigny predicted genes, only cloned genes were used for the sequence alignments. The respective accession numbers are as follows: Dicentrarchus labrax TNF $\alpha$ (ABB05053); Sparus aurata TNF $\alpha$ (CAC88353); Salvelinus fontinalis $\mathrm{TNF} \alpha$ (AAF86331); Danio rerio $\mathrm{TNF} \alpha$ (NP_001019618); Felis catus TNF $\alpha$ (CAA37948); Canis lupus familiaris TNF $\alpha$ (NP_001003244); Homo sapiens TNF $\alpha$ (NP_000585) and TNF $\beta$ (CAA26670); Rattus norvegicus TNF $\alpha$ (AAR91626); Mus musculus TNF $\alpha$ (BAA19513); Mustela putorius furo TNF $\alpha$ (ABN12939); Aotes vociferans TNF $\alpha$ (AAD01534); Aotes nigriceps TNF $\alpha$ (AAF21303); Ovis aries TNF $\alpha$ (CAA39437); Aotus nancymaae TNF $\beta$ (AAR22308); Canis familiaris TNF $\beta$ (AAR27884); Mus musculus TNF $\beta$ (CAA68529); Drosophila melanogaster EigerA (NP_724878); Drosophila melanogaster EigerB (NP_995791); predicted C. savigny TNF-1 (ID ENSCSAVP00000012224) and TNF-2 (ID ENSCSAVP00000019575), TNF $\alpha$-like $C$. intestinalis (AM 982527); Lumbricus terrestris CCF (AAL09587).

\section{Real-time PCR analysis}

Pharyngeal tissue expression of the CiTNF $\alpha$ gene was detected by real-time PCR with the Taqman method. Primers and hybridization probes were designed by using Primer Express software V.0 and synthesized commercially (Applied Biosystems, Foster City, USA). The Taqman probe sequence contained a $5^{\prime}$ FAM fluorophore and $3^{\prime}$ MGB quencher for the target gene (CiTNF $\alpha$ accession number AM982527) and $5^{\prime}$-VIC fluorophore and $3^{\prime}$. MGB quencher for the housekeeping gene $(C$. intestinalis actin accession number AJ297725). Real-time PCR analysis was performed on the Applied Biosystems 7500 real-time PCR System. Tissue expression was carried out in a $25-\mu 1$ PCR containing $2 \mu 1$ cDNA converted from $250 \mathrm{ng}$ total RNA, $100 \mathrm{nM}$ CiTNF $\alpha$ like probe, $400 \mathrm{nM}$ CiTNF $\alpha$-like forward (5'-GCCTCCCA TAGACCGTTGTTAA-3') and reverse (5'-CGGGA CACCTTCAGCACAT-3') primers, $100 \mathrm{nM}$ actin probe, $400 \mathrm{nM}$ actin forward (5'-TGATGTTGCCGCACTCGTA-3') and reverse (5'-TCGACAATGGATCCGGT-3') primers, and $12.5 \mu \mathrm{l}$ Taqman PCR Master Mix (Applied Biosystem). The 50 cycles of the two-step PCR program consisted of initial polymerase activation for $3 \mathrm{~min}$ at $95^{\circ} \mathrm{C}$ followed by denaturing step at $95^{\circ} \mathrm{C}$ for $15 \mathrm{~s}$, and then annealing/ extension was carried out at $60^{\circ} \mathrm{C}$ for $45 \mathrm{~s}$ when the fluorescent signal was detected. Each set of samples was run three times, and each plate contained quadruplicate cDNA samples and negative controls.

To obtain sample quantification, the $2^{-\Delta \Delta \mathrm{Ct}}$ method was used, and the relative changes in gene expression was analyzed as described in Applied Biosystems Use Bulletin N.2 (P/N 4303859). The amplification efficiencies of the target and reference gene were approximately equal thereby validating the $\Delta \Delta \mathrm{Ct}$ calculation. To assess whether two amplicons had the same efficiency, a sensitive method was used for checking the variation of $\Delta \mathrm{Ct}$ with template dilution. In this respect, serial dilutions $(1.0,0.5,0.2,0.1$, $0.05,0.02$, and 0.01 ) of cDNAs were amplified by real-time PCR with target and housekeeping-gene-specific primers,

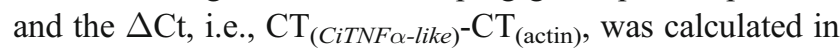
three replicates for each cDNA dilution. Data were fitted by using least-squares linear regression analysis. The amount of CiTNF $\alpha$-like transcript from the different tissues was normalized to actin in order to compensate for variations in input RNA amounts. Relative CiTNF $\alpha$-like expression was determined by dividing the normalized value of CiTNF $\alpha$ like expression in each tissue by the normalized value obtained from the untreated tissue.

\section{Histological methods}

For ISH studies, body wall (pharynx and tunic) fragments were fixed in Bouin's fluid (saturated picric acid:formaldehyde:acetic acid 15:5:1) for $24 \mathrm{~h}$, paraffin-embedded, and serially cut at $6 \mu \mathrm{m}$ (Leica RM2035 microtome, Solms, Germany). To identify the body wall tissues, sections were stained with Mallory Trichromic (Mahoney 1973; Mazzi 1977). Histological sections were examined under a Leica DMRE microscope.

\section{ISH assay}

To examine tissue excised from the inflamed body wall, ISH was carried out according to Le Guellec (1998), with digoxigenin-11-UTP-labeled transcripts $(1 \mu \mathrm{g} / \mathrm{ml}$ final concentration) according to the manufacturer's instructions (Roche Diagnostics). The riboprobe contained the sequence trait between positions $600-1080$ of the CiTNF $\alpha$-like cDNA. The re-hydrated histological sections were digested with proteinase $\mathrm{K}(10 \mu \mathrm{g} / \mathrm{ml})$ in phosphatebuffered saline (PBS) for 5 min, washed with PBS-T (PBS with $1 \%$ Triton $\mathrm{X}-100)$, and treated for hybridization with $50 \%$ formamide, $5 \times \mathrm{SSC}(1 \times \mathrm{SSC}$ : $0.15 \mathrm{M} \mathrm{NaCl} / 0.015 \mathrm{M}$ sodium citrate, $\mathrm{pH} 7), 50 \mu \mathrm{g} / \mathrm{ml}$ heparin, $500 \mu \mathrm{g} / \mathrm{ml}$ yeast tRNA, and $0.1 \%$ Tween 20 , at $37^{\circ} \mathrm{C}$ overnight. After exhaustive washes in PBS- $\mathrm{T}$ and $4 \times \mathrm{SSC}$ (twice for $10 \mathrm{~min}$ ), the sections were incubated for $1 \mathrm{~h}$ with antiDIG-Fab-AP conjugate (Roche Diagnostics) diluted 1:500 and washed in PBS-T. Finally, the sections were incubated in a 5-bromo-4-chloro-3-indolyl phosphate/nitro blue tetrazolium (BCIP/NBT) liquid substrate system (SigmaAldrich, Germany). Color development was stopped after 30 min at room temperature.

To examine cells from the hemolymph, each hemocyte preparation $\left(5 \times 10^{5}\right.$ in $\left.100 \mu \mathrm{l}\right)$ was placed on a Super Frost 
microscope slide for $30 \mathrm{~min}$ at $18^{\circ} \mathrm{C}$ and fixed with $100 \mu \mathrm{l}$ isotonic solution (0.01 M TRIS-HCl, $0.5 \mathrm{M} \mathrm{NaCl}, 4 \%$ paraformaldehyde, $\mathrm{pH} 7.4$ ) for $30 \mathrm{~min}$ at $18^{\circ} \mathrm{C}$. Cells were washed with PBS-T and treated for hybridization as above reported at $42^{\circ} \mathrm{C}$ overnight.

\section{Western blot analysis}

Following SDS-polyacrylamide gel electrophoresis (SDSPAGE; $12 \%$ acrylamide) of the hemocyte lysate supernatant or serum hemolymph ( $2 \mu \mathrm{g} /$ well protein content) according to the Laemmli method (1970), the gel was soaked in transfer buffer (20 mM TRIS, $150 \mathrm{mM}$ glycine, $\mathrm{pH} 8.8$ ) for $10 \mathrm{~min}$, and proteins were transferred $(1 \mathrm{~h}$ at $210 \mathrm{~mA})$ to a nitrocellulose sheet in transfer buffer. The filter was soaked for $2 \mathrm{~h}$ in blocking buffer $(0.14 \mathrm{M} \mathrm{NaCl}, 0.2 \mathrm{M}$ phosphatebuffered saline, $\mathrm{pH} 7.4$ ) containing $2 \% \mathrm{BSA}$ and $0.05 \%$ Tween-20, incubated with anti-hrTNF $\alpha$ monoclonal antibodies (1:2,500 in blocking buffer) for $1 \mathrm{~h}$, washed with blocking buffer, and incubated for $1 \mathrm{~h}$ with anti-mouse IgGalkaline phosphatase conjugate $(1: 15,000$ in blocking buffer). Finally, the nitrocellulose sheet was washed with PBS and assayed with $3 \mathrm{ml}$ BCIP/NBT liquid substrate system.

\section{Specificity of antibody reaction}

Monoclonal antibodies to human $\mathrm{TNF} \alpha(0.1 \mu \mathrm{l}$ of $2.5 \mu \mathrm{g} / \mu \mathrm{l}$; Abcam) were absorbed overnight at $4^{\circ} \mathrm{C}$ with $125 \mu \mathrm{l}$ hrTNF $\alpha(10 \mu \mathrm{g} / \mathrm{ml}$; Sigma-Aldrich) and centrifuged at $27,000 \mathrm{~g}$ for $45 \mathrm{~min}$ at $4^{\circ} \mathrm{C}$. Non-absorbed monoclonal anti$\mathrm{hrTNF} \alpha \operatorname{IgG}$ at the same dilution $(1: 2,500)$ as the absorbed IgG was used as a control in Western blot assays.

\section{Statistical methods}

Student's $t$-test was used to estimate statistical significance. Multiple comparisons were performed with one-way analysis of variance (ANOVA), and different groups were compared by using Tukey's $t$-test. Standard deviations were calculated based upon at least three experiments, each being analyzed in triplicate. $P<0.01$ was considered statistically significant.

\section{Results}

Analysis of $\mathrm{CiTNF} \alpha \mathrm{cDNA}$ and sequence

A BLAST search (Ensemble) of the human TNF $\alpha$ amino acid sequence viewed in genomic alignment with $C$. intestinalis identified the predicted genes showing the following similarity (SP) and identity percentages (IP) with
TNF family components: (1) ENSCINP00000023425, 56.9 SP and 27.8 IP with a TRAIL-like protein (TNFrelated apoptosis-inducing ligand) of $D$. rerio; (2) ENSCINP00000000806, 62.7 SP and 29.7 IP with the bovine ectodysplasin A; (3) ENSCINP00000026947, 57.0 SP and 28.9 IP with rabbit lymphotoxin- $\alpha$ precursor; (4) ENSCINP00000016689 54.4 SP and 23.5 IP with feline Fas ligand. Finally, the gene ENSCING00000008162 presented 56.0 SP and 22.7 IP with TNF $\alpha$ of the monkey Aotes vociferans, and 26.7 SP and 14.0 IP with human $\mathrm{TNF} \alpha$. This gene was found on $C$. intestinalis chromosome $3 q$ at location 3.721.426-3.738.314.

The BLAST search also identified, in the C. savigny (Cs) genome, two TNF-like predicted genes (ID ENSCSAVP00000012224, ID ENSCSAVP00000019575): CsTNF1 presented 58.9 SP and 25.2 IP to fish (Larimichthys crocea) TNF $\alpha$, and CsTNF2 60.8 SP and $24.5 \mathrm{IP}$ to pafferfish (Fugu rubripes) TNF $\alpha$.

CiTNF $\alpha$-like cDNA was produced by reverse-transcription of mRNA extracted from the pharynx of ascidians $4 \mathrm{~h}$ after inoculation of LPS. By using the primer pairs shown in Table 1, two overlapping parts of $700 \mathrm{bp}$ and $600 \mathrm{bp}$ were obtained (for the consensus sequence, see Fig. 1). An open reading frame (ORF) of 936 bp encoding a propeptide of 312 amino acid, with a predicted molecular size of $35.451 \mathrm{kDa}$ and a theoretical isoelectric point $(\mathrm{p} /)$ of 9.4, was deduced. A search for the $\mathrm{p} I$ of the deduced mature protein gave a similar value ( $\mathrm{p} I$ 9.5). The peptide LQIQGTGQYLVYMHTTF representing the TNF family signature ([ILV]-X-I-X3_G-X-[ILV]-[HY]-X-[KQR]-X2[FLV]) was located at position 185-201.

A transmembrane domain (7-29 position) was detected by the TMHMM2 program, whereas the SignalP-NN program (included in ExPASy) predicted a signal peptide at amino acid positions 1-23. However, a search with the Phobius program (http://phobius.sbc.su.se/) clearly predicted the transmembrane domain at positions 6-29.

Based on similarities with other TNF sequences, a putative TNF-converting enzyme (TACE) cleavage site (Thr127-Leu128) was identified; a cleavage at this position would give a mature peptide of 185 amino acids (20.952 kDa deduced molecular size). Two potential N-glycosylation sites, NESC (60-63) and NCSR (156-159), were predicted by the NetNGlyc 1.0 program. Finally, two conserved Cys residues (Cys221, Cys248) could form an intra-chain disulphide bridge. In general, the sequence comparison showed a higher similarity of the mature peptide sequence (from the TACE cut site to C-terminal end of the protein) to TNFs from the examined species than that of the propeptide N-terminal end (from the beginning of the propetide to the TACE cleavage site) in which the transmembrane domain was located (Table 2). 
Fig. 1 Nucleotide and deduced amino acid sequences of TNF $\alpha$ like cDNA from Ciona intestinalis pharynx $4 \mathrm{~h}$ after LPS inoculation (light gray shading transmembrane domain at positions 6-29, mid-gray shading mature peptide is found at positions 139-312, dark gray shading TNF family signature at positions 185-201). The TACE cleavage site (positions 127128), N-glycosylation sites (NESC 60-63, NCSR 156-159), Cys 221, and Cys 248 are indicated in bold and underlined

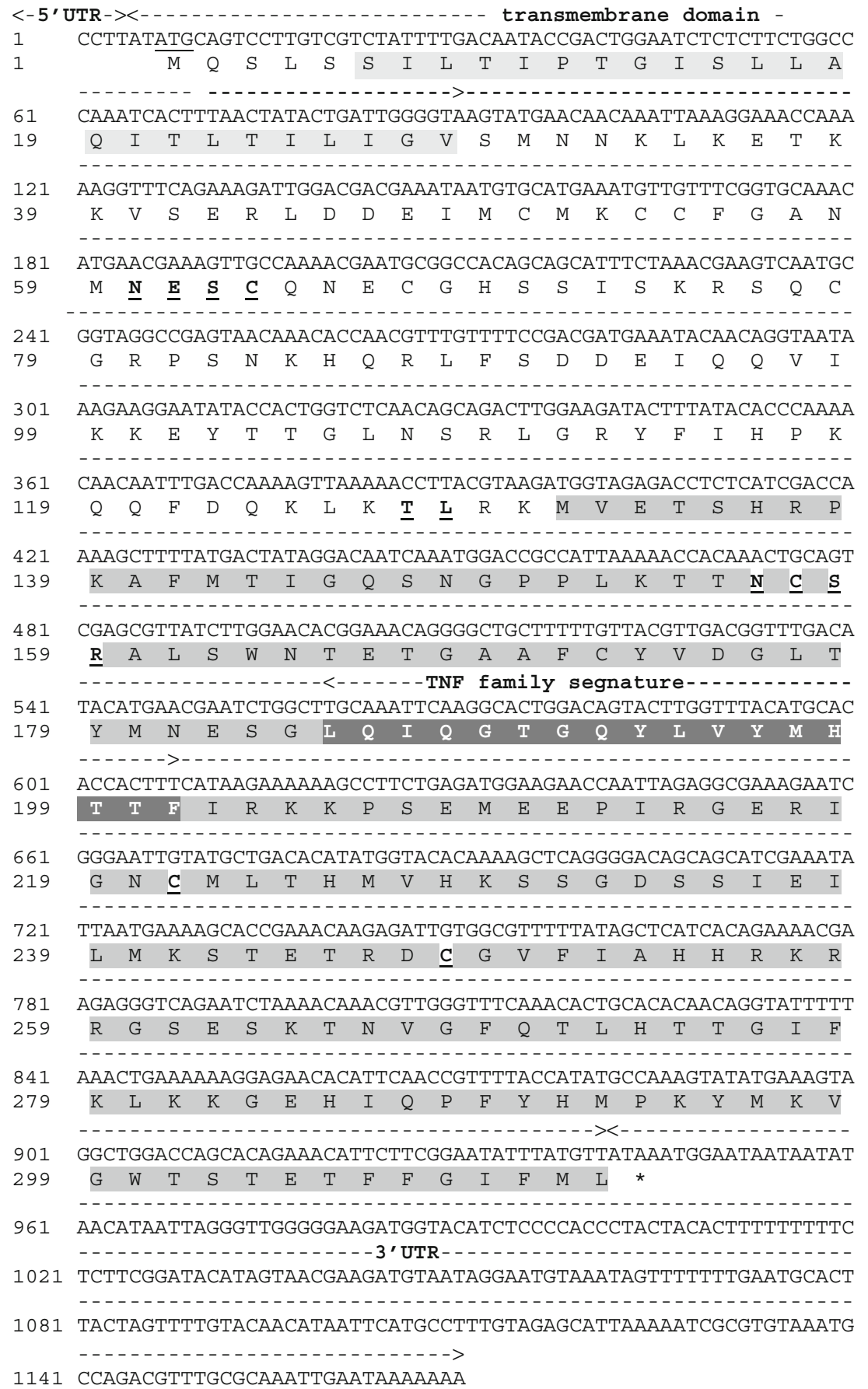

Sequence comparison and phylogenetic analysis

The CiTNF $\alpha$-like amino acid sequence was aligned with the CsTNF-1 sequence and with the TNF $\alpha$ sequence of the fish $D$. rerio, both of which showed the highest SP, and with the human TNF $\alpha$ (Fig. 2). The alignments were obtained with ClustalX v.1.81 and similarity shaded with GeneDoc v.2.6.002. The CiTNF $\alpha$-like deduced protein sequence showed $36.9 \mathrm{SP}$ and $16.2 \mathrm{IP}$ with $D$. rerio, 54.8 SP and 38.8 IP with CsTNF-1, and 52.4 SP and 34.9 IP with CsTNF-2. A similar full sequence length of the ascidian TNF was found (279 or 312 ), whereas both were 80-90 residues longer than the vertebrate ones.

A domain comparative analysis is presented in Table 2. The highest similarity and identity percentages of the TNF family domain were between $\operatorname{CiTNF} \alpha$-like sequences and 
Table 2 Identity $(I P)$ and similarity $(S P)$ percentages of Ciona intestinalis $\mathrm{TNF} \alpha(C i T N F \alpha)$ domains with the corresponding sequences from $D$. rerio $(D r T N F \alpha)$, human $(h T N F \alpha)$, and C. savigny $(C s T N F)$ showing the number of amino acids (round brackets) and resudue positions (square brackets)

\begin{tabular}{lllll}
\hline CiTNF domain (312) & hTNF $\alpha$ (232) & DrTNF $\alpha$ (242) & CsTNF-1 (309) & CsTNF-2 (279) \\
\hline Signal peptide [1-23] & Absent & Absent & 10.7 IP, 7.9 SP [1-18 ] & 10.0 IP, 20.0 SP [1-22] \\
Transmembrane [7-29] & 6.2 IP, 15.6 SP [35-57] & 12.9 IP, 19.4 SP [38-60] & 11.8 IP, 14.7 SP [7-26] & 8.6 IP, 8.6 SP [7-26] \\
TNF family (173) [139- & 19.3 IP, 37.6 SP (145) & 15 IP, 33.3 SP (129) [113- & 45.7 IP,62.4 SP (168) & 35.6 IP, 49 SP (140) [139- \\
312] & [87-23] & 242] & [141-309] & $279]$ \\
\hline
\end{tabular}

CsTNF-1 (62.4 SP, 45.7 IP:), whereas 50.0 SP and 35.6 IP distinguished CiTNF $\alpha$-like sequences and CsTNF-2. High similarity percentages were observed by comparing ascidian and vertebrate TNF family domains: $33.0 \mathrm{SP}$ and 15.0 IP to D. rerio; $37.0 \mathrm{SP}$ and $19.0 \mathrm{IP}$ to human.

The phylogenetic tree was constructed by analyzing the deduced amino acid sequences of the previously cloned TNF genes of invertebrates and vertebrates. The $C$. savigny predicted TNF genes were included considering them as orthologous in the divergence of two congeneric species. Three main clusters were found (Fig. 3). The first one included mammalian $\mathrm{TNF} \alpha$ and $\operatorname{TNF} \beta$, the second one grouped fish TNF $\alpha$, and the last one was made up of $C$. intestinalis and C. savigny TNFs. D. melanogaster Eiger A and B TNF homologs formed a group clearly separated from the chordate TNFs. Ascidian TNF group was far removed from the mammalian TNF cluster and closer to the fish group. Notably, in this tree, mammalian TNF $\alpha$ was grouped separately from TNF $\beta$, and the chordate cluster (vertebrate+ ascidians) and $L$. terrestris CCF were widely separated.

Real-time PCR analysis demonstrates that CiTNF $\alpha$-like expression is promptly upregulated following in vivo LPS inoculation

The relative efficiency plots (log cDNA dilution versus $\Delta \mathrm{Ct}$ ) of the amplification of the CiTNF target gene and of the internal control (actin), examined by real-time PCR and Taqman detection, confirmed that the gene-specific primers had similar amplification efficiency, and that the absolute value of the slope was close to zero (0.071; Fig. 4). Quantitative mRNA expression in the inflamed pharynx excised from ascidians after an in vivo LPS challenge showed enhanced levels in CiTNF mRNA expression
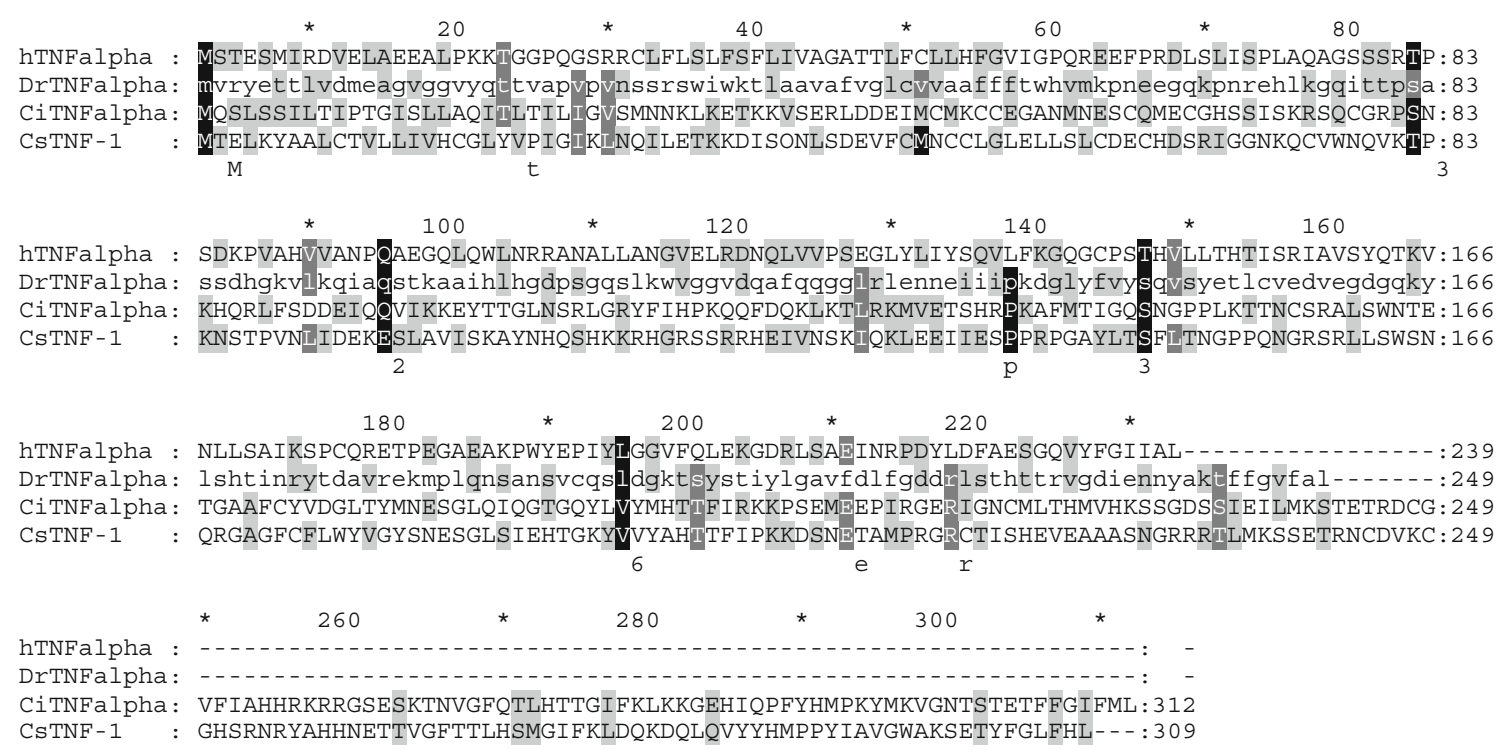

Fig. 2 Deduced amino acid sequence of $C$. intestinalis (CiTNFalpha) TNF $\alpha$ cDNA aligned with human (hTNFalpha) and D. rerio (DrTNFalpha) TNF $\alpha$ cDNA, and the C. savigny (CsTNF-1) predicted sequence. The alignments were obtained with ClustalX v.1.81 and similarity shaded with GeneDoc v.2.6.002. Invariant residues are shaded in black, conserved residues in $80 \%$ of the sequences are shaded in gray with white lettering; conservatively substituted residues in $60 \%$ of sequences are shaded in gray with black lettering (stars blocks of 20 amino acid residues) 


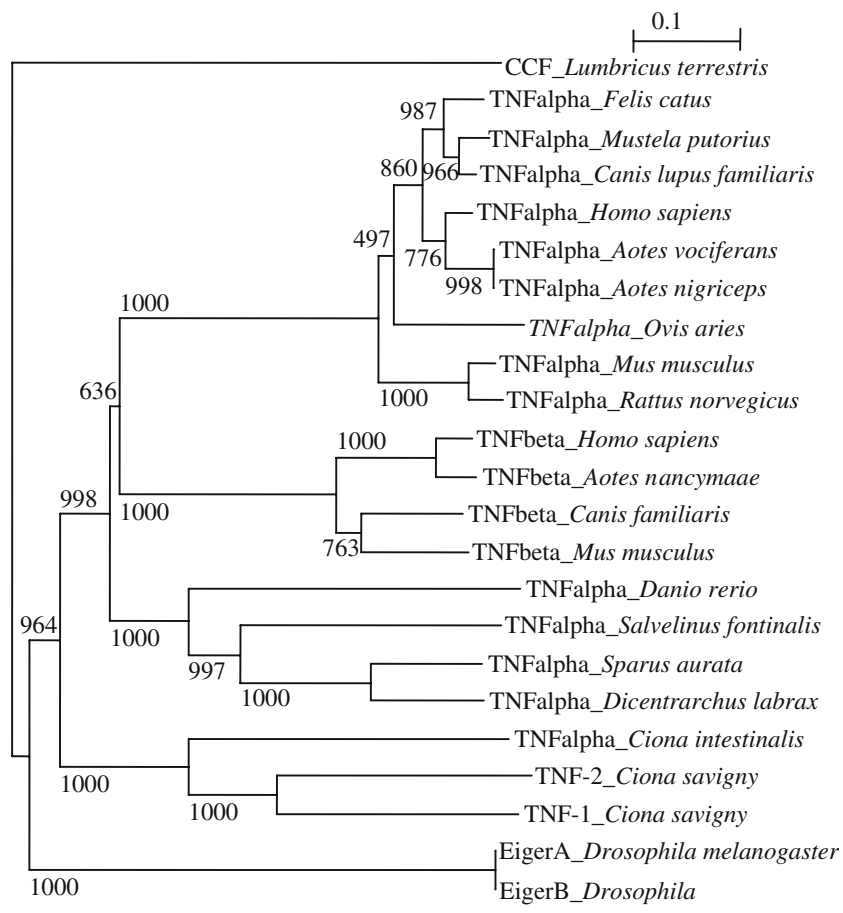

Fig. 3 Phylogenetic tree of mammal, fish, and invertebrate deduced amino acid sequences for TNF and TNF-like cDNAs. To evaluate congeneric relationships, deduced amino acid sequences of the predicted C. savigny TNF-1 and TNF-2 genes were also included. The tree was constructed by the neighbor-joining method and bootstrap analysis. Numbers represent the percentages of 1000 bootstrap replicates in which the same internal branch was recovered. Bar 0.1 (number of amino acid residues substitutions for site). Annelids: L. terrestris. Insect: D. melanogaster. Ascidians: predicted Ciona savigny, C. intestinalis. Fish: D. labrax, S. aurata, S. fontinalis, $D$. rerio. Mammals: $R$. norvegicus, $M$. musculus, $M$. putorius furo, $F$. catus, $C$. lupus familiaris, $C$. familiaris, $O$. aries, A. nigriceps, $A$. nancymaae, $H$. sapiens

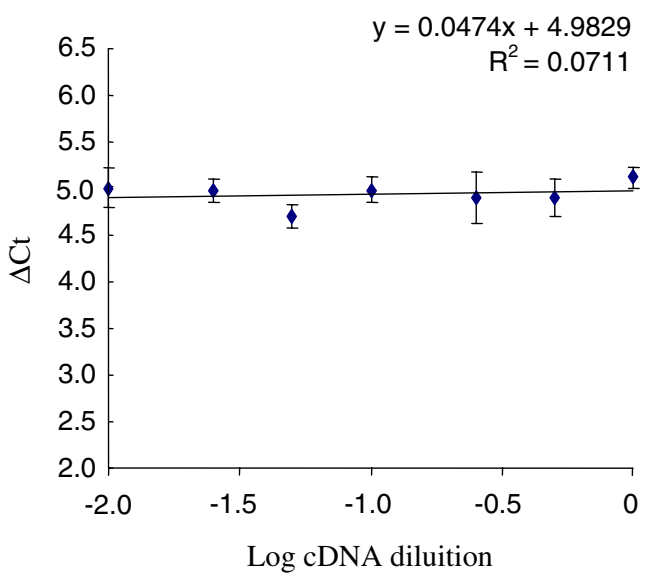

Fig. 4 Relative efficiency plot of amplification of target gene (CiTNF) and internal control (actin) examined by real-time PCR and Taqman detection. Serial dilutions of cDNA were amplified by using gene-specific primers. The $\Delta \mathrm{Ct}[\mathrm{CT}(\mathrm{TNF} \alpha$-like)-CT(actin) $]$ was calculated for each cDNA dilution. Data were fitted by using least-squares linear regression analysis $\left(y=0.0474 \mathrm{x}+4.9829, \mathrm{R}^{2}=0.0711\right) ; n=3$
(Fig. 5). At each time point $(0,1,2,4,8,12,24,48 \mathrm{~h})$ of three experiments, the kinetics of gene expression was analyzed in four distinct pharynx samples. Low constitutive gene expression was maintained in naive ascidian tissues until the end of the experiment. LPS upregulated the gene activity, which was evident as early as $2 \mathrm{~h}$, gradually increasing and reaching a maximum at $4 \mathrm{~h}$, and then decreasing at $8 \mathrm{~h}$. High expression levels were maintained from $8 \mathrm{~h}$ to $24 \mathrm{~h}$ in comparison with the ascidians injected only with MS. To evaluate the inducing effect of LPS explants, a same number of MS-injected ascidians were analyzed and compared with the LPS-injected ascidians. At $4 \mathrm{~h}$, when the gene expression attributable to the LPS treatment had reached a peak, a significantly lower effect was exerted by MS inoculation (Fig. 5).

ISH assay shows that $\mathrm{CiTNF} \alpha$-like is expressed by hemocytes in inflamed body wall tissue

Histological transverse sections from naive ascidian body wall after Mallory staining showed the tunic matrix, the epidermis lining the tunic, the connective tissue under the epidermis with lacunae of the open circulatory system, and the pharynx (Fig. 6a). The tunic matrix presented scattered hemocytes, whereas the epidermis monolayer lined the matrix and was in contact with the connective tissue situated below and containing the longitudinal and circular muscles. The pharynx bars (folds) were provided with vessels containing hemocytes (Fig. 6a).

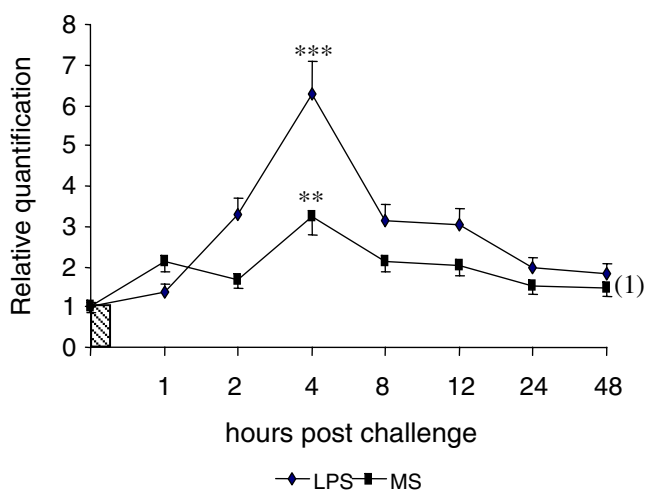

Fig. 5 Real-time PCR analysis. Time-course of CiTNF $\alpha$-like gene expression in Ciona intestinalis pharynx after inoculation of $100 \mu \mathrm{g}$ bacterial lipopolysaccharide (LPS) into the body wall (filled diamonds), compared with the gene expression in ascidians injected with $100 \mu 1$ marine solution (MS; filled squares). Values, plotted as mean $\pm \mathrm{SD}$, were inferred from four ascidians examined in three distinct experiments; each assay was performed in triplicate. Significance was evaluated by comparing the values with the expression level of untreated pharynx from four ascidians (open box naive ascidians). ${ }^{* *} P<0.01,{ }^{* * *} P<0.001$. ${ }^{(1)}$ Multiple comparisons of the time-course profiles were performed with one-way analysis of variance (ANOVA), and the different groups were compared by the Tukey $t$-test 
Fig. 6 In situ hybridization assay of transverse sections of the body wall and of hemocytes from $C$. intestinalis $4 \mathrm{~h}$ after LPS inoculation. a Mallory staining of histological transverse sections from naive ascidians. Tunic matrix $(\mathrm{tm})$, epidermis (ep) lining the tunic, connective tissue $(\mathrm{co})$ under the epidermis with lacunae (lac) of the open circulatory system and muscles, and pharynx bars $(p h b)$ containing hemocytes. Bar $100 \mu \mathrm{m}$. Histological sections of body wall (b-d) and circulating hemocytes $(\mathbf{e}, \mathbf{f})$ from ascidians $4 \mathrm{~h}$ after LPS inoculation. Bars $10 \mu \mathrm{m}$. b Tunic matrix $(\mathrm{tm})$, amoeboid hemocytes $(a h)$. c Pharynx bars $(p h b)$, granular hemocytes $(g h)$, endothelium (en). d Connective tissue (co), granular hemocytes $(g h)$, muscles $(m)$. e Hyaline amoebocytes $(h a)$, large granular hemocytes $(\lg h)$. f Negative control with the sense strand

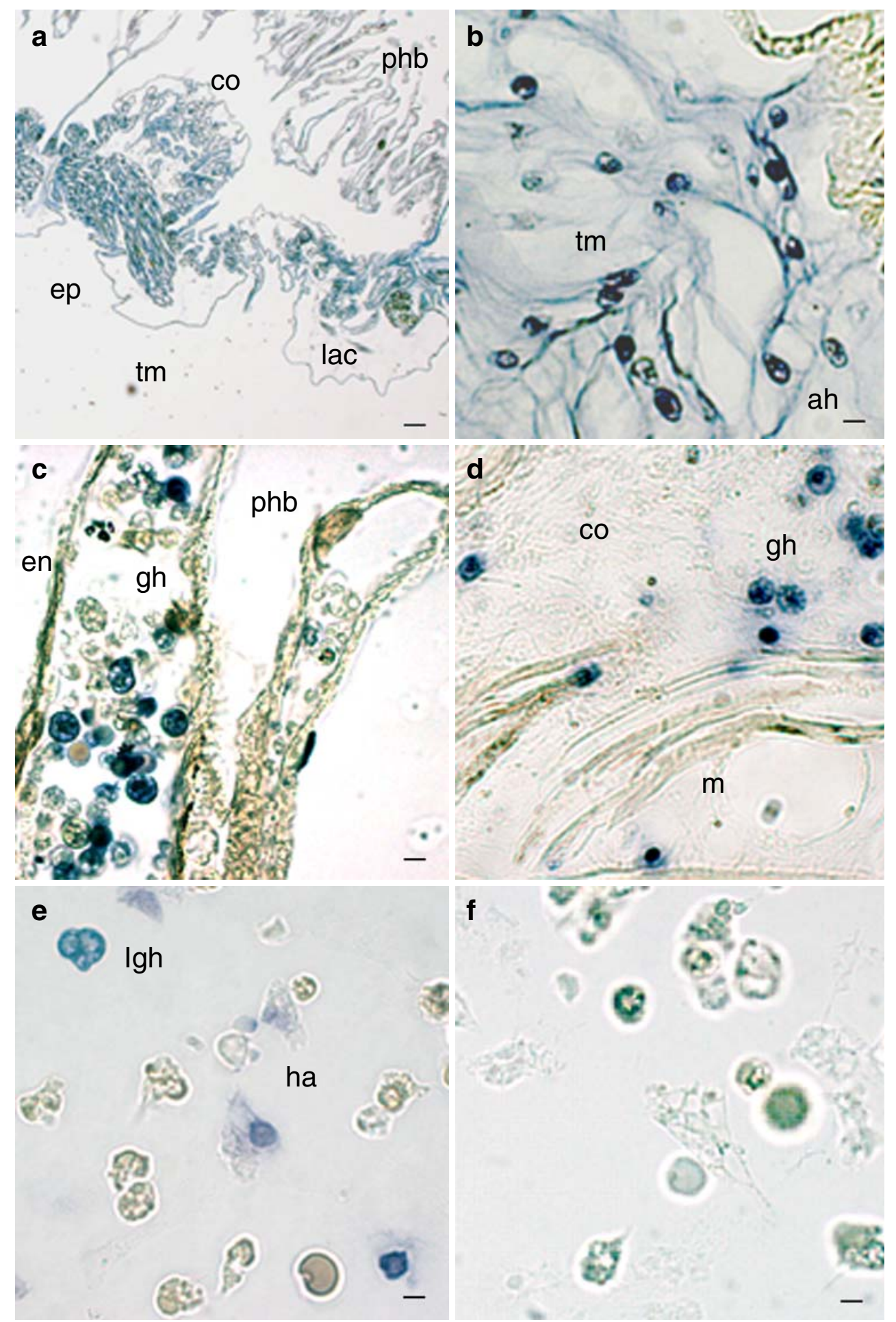

At $4 \mathrm{~h}$ after LPS inoculation, ISH analysis of histological sections of the body wall showed that granular amoebocytes, which infiltrated the inflamed tunic (Fig. 6b), and hemocytes, which possessed large granules, were contained in the pharynx bars (Fig. 6c), and were scattered in the connective tissue lining the tunic (Fig. 6d), expressed CiTNF $\alpha$-like mRNA. The riboprobe appeared to be mainly localized in the nucleus and in the cytoplasmic rim lining the granules; these results were confirmed by examining tissues from four ascidians. Although cell counts were not carried out, the cytokine-expressing hemocytes were clearly more numerous in the body wall of the ascidians at $4 \mathrm{~h}$ after the LPS challenge, whereas at 24-48 h, few cells encoded the transcript. Accordingly, a few positive cells were observed in ascidians $4 \mathrm{~h}$ after the MS inoculation; such cells were rare in sections from naive ascidian (not shown). 
Similar results were obtained by examining circulating hemocytes from the hemolymph withdrawn $4 \mathrm{~h}$ after LPS challenge. In Fig. 6e, hyaline amoebocytes and hemocytes with large granules were positive, whereas unilocular refractile granulocytes were not.

Negative controls with the sense-strand probe showed no signal, either in tissues (not shown) or in circulating hemocytes (Fig. 6f).

hrTNF $\alpha$ epitopes are displayed by serum and hemocytebound protein components

Western blot analysis with monoclonal anti-hrTNF $\alpha$ antibodies of serum hemolymph and hemocyte lysate supernatants was carried out. Each sample was prepared as a pool from 10 ascidians at each time point after LPS inoculation, and three distinct experiments were analyzed. The antibodies cross-reacted with a $15.6 \pm 0.42 \mathrm{kDa}$ serum component and a $43.5 \pm 1.78 \mathrm{kDa}$ protein in the hemocyte lysate supernatants. In Fig. 7, a densitometric analysis of the bands shows that LPS challenge can modulate the expression level both in the serum and in circulating hemocytes. In the serum from naive ascidians, the density of the $15.6-\mathrm{kDa}$ band was low, whereas it appeared to be

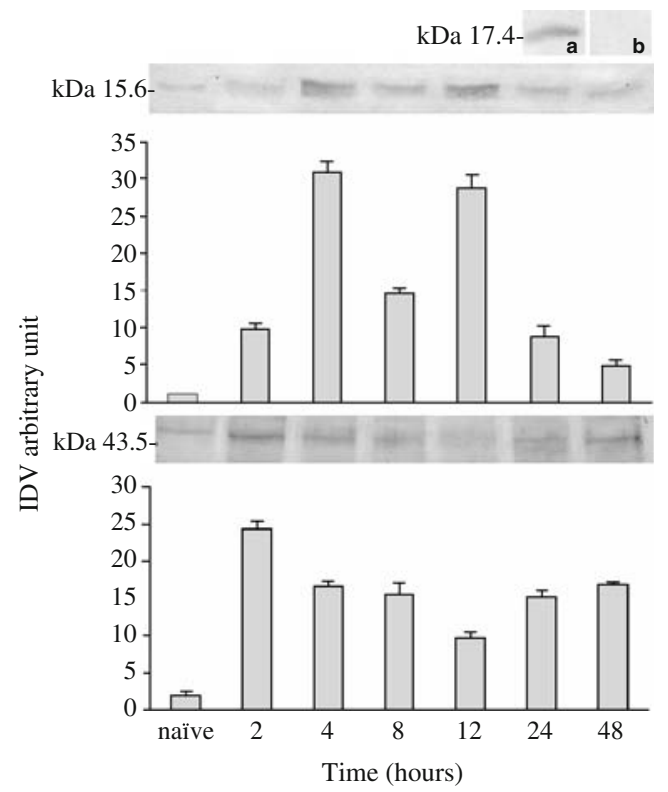

Fig. 7 Western blot and densitometry analyses with monoclonal antirhTNF $\alpha$ antibodies of Ciona intestinalis serum hemolymph (top) and hemocyte lysate supernatant (bottom) prepared from ascidians at 0 - to 48-h time points after LPS inoculation. Each sample prepared as a pool of 10 ascidians was from three distinct experiments. Mean size values are reported $( \pm \mathrm{SD})$. Inset (top right): $\mathrm{hrTNF} \alpha(30 \mathrm{ng}) 17.4-\mathrm{kDa}$ band recognized by the antibodies (lane $a$ ) as a positive control. Serum sample prepared $4 \mathrm{~h}$ after LPS inoculation assayed with antibody preparation absorbed with $\mathrm{hrTNF} \alpha$ showing no bands (lane $b)$, even with secondary antibodies significantly enhanced at $4 \mathrm{~h}$ (Fig. 7, top). Similar expression levels were found by examining the hemocyte lysate supernatant in which the $43.5-\mathrm{kDa}$ band density peaked at $2 \mathrm{~h}$, whereas in naive ascidians, the band density was low (Fig. 7, bottom). Occasionally, the smaller band could also be found in hemocyte lysate preparations (not shown).

The bands were not observed when secondary antibodies only or antibody preparations absorbed with hrTNF $\alpha$ were used; the inset in Fig. 7 shows the Western-blotted band of $\operatorname{hrTNF} \alpha(17.4 \mathrm{kDa})$ after reaction with the specific antibodies, and the absence of bands when the serum was assayed with the absorbed antibodies. The same result was found when the hemocyte lysate preparation was tested with the absorbed antibodies (not shown).

\section{Discussion}

Successful survival of invertebrates is mainly linked to a variety of innate defence pathways against microbial pathogens. In ascidians, the innate immune responses include cytokine-like humoral molecules and functional analogs of vertebrate inflammatory cytokines, including TNF $\alpha$ (Beschin et al. 2001; Beck 1998). We have cloned and sequenced, for the first time, a TNF $\alpha$-like cDNA from Ciona intestinalis (CiTNF $\alpha$-like) challenged in vivo with LPS, a potent stimulator of proinflammatory cytokines, and have shown that the time-course of expression of the CiTNF $\alpha$-like gene is modulated by the challenge. The cDNA was obtained by reverse-transcription of mRNA extracted from the ascidian pharynx $4 \mathrm{~h}$ after LPS inoculation, and suitable primer pairs were used to obtain the consensus sequence. The 936-bp ORF is equivalent to 312 amino acids with a predicted molecular size of $35 \mathrm{kDa}$, and the gene is located on chromosome $3 \mathrm{q}$ of $C$. intestinalis. When the BLAST search was carried out, four more $C$. intestinalis predicted genes, related to TNF family members, were found, including a TRAIL-like protein (TNF-related apoptosis-inducing ligand) of $D$. rerio, the bovine ectodysplasin $\mathrm{A}$, the rabbit lymphotoxin- $\alpha$ precursor, and the feline Fas ligand. Since, in mammals, these members are type II membrane glycoproteins with limited homology to $\mathrm{TNF} \alpha$ in the extracellular region, they were not studied further. Finally, the gene with significant predicted similarity and identity to TNF $\alpha$ of the monkey Aotes vociferans and human $\mathrm{TNF} \alpha$ was cloned and sequenced.

The multiple alignments of the amino acid sequence of the CiTNF $\alpha$-like protein with TNF $\alpha$ family members (Bodmer et al. 2002) and the domain analysis based on similarities to other TNFs disclosed a transmembrane domain at positions 7-29 containing a classical peptide 
signal at positions 1-23 and a Leu22-Thr23 predicted cleavage site (Idriss and Naismith 2000). Such a signal peptide could not be identified in the corresponding domain of mammals and the majority of fish species, whereas it has been predicted (positions 1-51) in the turbot (fish) TNF $\alpha$ transmembrane domain (positions 35-55; Ordás et al. 2007). The high similarity between the hydrophobic regions of a transmembrane chain and that of a signal peptide might lead to cross-reaction between the two types of predictions (Käll et al. 2004); therefore, a search with the Phobius program, a combined transmembrane topology and signal peptide predictor, was carried out, and the transmembrane domain was clearly predicted at positions 6-29. The TNF family domain of the CiTNF $\alpha$-like protein showed $37 \%$ similarity with hTNF $\alpha$ and $33 \%$ with $D$. rerio. Finally the similarity increased up to $45 \%$ with $C$. savigny TNF1.

As in mouse (Black et al. 1997) and fish (see Ordás et al. 2007), the presence of a potential transmembrane domain with a conserved putative TACE cleavage site at Thr127Leu128 suggests that CiTNF $\alpha$-like protein might also be found as a membrane-bound form and indicates that proteolysis of the precursor can produce the mature protein of 185 amino acids. The protein structure might be stabilized by an intrachain disulphide bridge associated with the two conserved Cys residues (Cys221, Cys248; Rink and Kirchner 1996). Like the turbot propeptide, which is glycosylated at positions 57 and 184 (Ordás et al. 2007), two predicted potential N-glycosylation sites (NESC 60-63 and NCSR 156-159) indicate that the CiTNF $\alpha$-like propeptide might also be glycosylated, but only the second site has been found in the mature cytokine.

In brief, $\mathrm{CiTNF} \alpha$-like protein appears to be a type II transmembrane protein with an extracellular C-terminal domain that may be glycosylated and released as a soluble cytokine upon proteolytic processing (Bodmer et al. 2002). The domain similarity to mammals and/or cloned fish TNF $\alpha$ (Idriss and Naismith 2000; Goetz et al. 2004; Ordás et al. 2007) has led us to identify the CiTNF $\alpha$-like polypeptide as a component of the TNF $\alpha$ family. A striking feature of the deduced amino acid sequence is the theoretical $\mathrm{p} I$ of 9.4, which is higher than that of vertebrate $\mathrm{TNF} \alpha(\mathrm{p} I$ 5.0-5.6) presumably bcause of the high basicity of the 42 positively charged Arg and Lys residues in the CiTNF $\alpha$-like sequence. Since the theoretical $\mathrm{p} I$ of the predicted mature protein gives the same value $(\mathrm{p} I$ 9.51), the possibility that the premature protein shifts the $\mathrm{p} I$ toward acidity in the mature protein can be excluded. Although we are unable to explain the functional meaning of such a property, the basicity might play a role in stabilizing the protein in the membrane and might also be related to the presence of degradative enzymes in that particular localization (Schwartz et al. 2001; Kiraga et al. 2007).
As shown by the phylogenetic tree, $\operatorname{CiTNF} \alpha$-like protein and the predicted $C$. savigny TNF-1 and TNF-2 form a cluster related to the vertebrate cluster suggesting that the TNF $\alpha$ family domain and cytokine-like activities were once present in the ancestor common to the vertebrate and ascidian lineages. In this respect, it is noteworthy that $D$. melanogaster TNF $\alpha$ homologs, the Eiger A and B isoforms, appear to be distant from the chordate group, and the Lumbricus CCF, reported as a functional analog (Silerova et al. 2006), also lies far from the TNF family.

Since functional homologies could support the characterization of a $\mathrm{TNF} \alpha$-like cytokine, an inflammatory reaction was challenged in the $C$. intestinalis body wall by inoculation with LPS; upregulation and a time-dependent expression of the CiTNF $\alpha$-like gene were observed. The body wall in which the LPS was injected is mainly formed (from the inner to the outer part) of the pharyngeal sac comprising of bars containing hemocytes and hemopoietic nodules (De Leo et al. 1987), the connective tissue with scattered hemocytes and hemopoietic nodules (Ermak 1976), and the tunic with few hemocytes in the matrix, which is lined with the epidermal monolayer. These tissues appear to be stimulated by the inflammatory agent, and many hemocytes promptly occupy the inflamed tunic matrix, presumably originating from the pharynx and connective tissue. Like vertebrate TNF, CiTNF $\alpha$-like protein was constitutively expressed in the examined tissues and was upregulated by in vivo LPS inoculation. The mRNA expression (real-time PCR) levels in pharynx tissues at $0,2,4,8,12$, and $24 \mathrm{~h}$ time-points were compared with those of controls from naive ascidians and ascidians after MS inoculation. A low level of TNF $\alpha$-like transcript was constitutively expressed in naive ascidians, whereas expression was promptly $(4 \mathrm{~h})$ but barely enhanced after MS inoculation, indicating the triggering of a host inflammatory response associated with the MS injection procedure. The LPS challenging effect was clearly shown by the significantly higher mRNA expression at $4 \mathrm{~h}$ and then a decrease with a profile similar to that of mouse and fish TNF $\alpha$ with a half-life estimated at only 40-45 min (Mijatovic et al. 2000; MacKenzie et al. 2003). In spite of such a decrease, the expression level was maintained above that caused by the MS injection alone, probably as an effect of the protracted inflammatory action differently exerted by LPS on the body wall tissues.

ISH assay of histological sections from ascidians sampled at $4 \mathrm{~h}$ after LPS inoculation demonstrated that CiTNF $\alpha$-like mRNA is mainly expressed by granulocytes that populate the inflamed tunic matrix lining the epidermis and are known to be inflammatory cells (Parrinello et al. 1984a, 1984b). Identification of the precise hemocyte type in the histological sections after treatment for ISH assay was difficult; however, microsco- 
py observations showed the main features of granular amoebocytes and granulocytes with large granules that were abundant in the tunic at the beginning of the inflammatory response (Parrinello 1996; Parrinello et al. 2007; Vizzini et al. 2008). Although cell counts were not carried out, a lower proportion of positive hemocytes were observed both in naive ascidians and in those inoculated with MS only. In the circulating hemolymph at $4 \mathrm{~h}$ after LPS injection, hemocytes with large granule and hyaline amoebocytes, which have been reported to be phagocytes (Rowley 1981), were stained by the riboprobe. Unilocular refractile granulocytes and various transitional forms of granulocytes, which were abundant in the inflamed tunic matrix, did not present transcript signal. These results on body wall tissues and hemolymph strongly suggest that the CiTNF $\alpha$-like protein exerts an important role in both local and systemic responses to inflammation, as is also indicated by the presence of soluble and cell-bound cytokine forms in the hemolymph. Indeed, monoclonal antibodies against $\mathrm{hrTNF} \alpha$ recognize a $43-\mathrm{kDa}$ protein in the hemocyte lysate supernatant, and a $15-\mathrm{kDa}$ soluble form in the serum after Western blot analysis. Differences in size between the values $(35 \mathrm{kDa}$ and $20 \mathrm{kDa})$ predicted from the deduced sequence and those recorded by SDSPAGE might be attributable to the processes that lead to the mature protein structure, and to the methods used for the analyses. Nevertheless, we show here that, like TNF $\alpha$ in mammals (Idriss and Naismith 2000) and fish (Goetz et al. 2004), CiTNF $\alpha$-like protein is present both in a cellbound and soluble form. Although isolated fractions have not been examined, the reproducability of the cell-bound form, even in the presence of detergent and the antiprotease cocktail in the hemocyte lysate preparation, suggests that the $43-\mathrm{kDa}$ band represents a membraneassociated form that might be processed before being released. Densitometry analysis has confirmed that this cytokine-like gene is modulated in its expression by the LPS challenge, and that the band density of the soluble form is enhanced in the serum at $4 \mathrm{~h}$, and that of the cellbound form at $2 \mathrm{~h}$. The serum protein expression profile is coincident with the gene expression, as revealed by the real-time PCR analysis of the pharynx. The anticipated expression $(2 \mathrm{~h})$ of the cell-bound form in circulating hemocytes appears to be congruent with a presumed maturation process of the soluble form.

In conclusion, the cDNA and deduced amino acid sequence and the LPS challenged gene expression have demonstrated unequivocally the involvement of a soluble and a cell-bound form of CiTNF $\alpha$-like protein in the ascidian inflammatory response. A phylogenetic relationship is manifest between ascidian and vertebrate proinflammatory TNF $\alpha$. Further research is in progress to reveal the functional properties of this ascidian cytokine.
Acknowledgements We thank Mr. G. Miceli for collecting ascidians, and Mr. M. Guarcello for expert maintenance of the aquaria.

\section{References}

Akira S, Hirano T, Taga T, Kishimoto T (1990) Biology of multifunctional cytokines: IL 6 and related molecules (IL 1 and TNF). FASEB J 4:2860-2867

Ballarin L, Franchini A, Ottaviani E, Sabbadin A (2001) Morula cells as the major immunomodulatory hemocytes in ascidians: evidences from the colonial species Botryllus schlosseri. Biol Bull 201:59-64

Beck G (1998) Macrokines: invertebrate cytokine-like molecules? Front Biosci 16:559-569

Beschin A, Bilej M, Torreele E, De Baetselier P (2001) On the existence of cytokines in invertebrates. Cell Mol Life Sci 58:801-814

Beschin A, Bilej M, Lucas R, De Baetselier P (2003) Functional convergence of invertebrate and vertebrate cytokine-like molecules based on similar lectin-like activity. In: Beschin A (ed) Progress in molecular and subcellular Biology. Invertebrate cytokines. Springer, Berlin Heidelberg New York, pp 145-163

Betti M, Ciacci C, Lorusso LC, Canonico B, Falcioni T, Gallo G, Canesi C (2006) Effects of tumour necrosis factor $\alpha$ (TNF $\alpha$ ) on Mytilus haemocytes: role of stress-activated mitogen-activated protein kinases (MAPKs). J Biol Cell 98:233-244

Bilej M, Joskova R, Van den Bergh R, Prochazkova P, Silerova M, Ameloot P, De Baetselier P, Beschin A (2006) An invertebrate TNF functional analogue activates macrophages via lectin-saccharide interaction with ion channels. Int Immunol 18:1663-1670

Black RA, Rauch CT, Kozlosky CJ, Peschon JJ, Slack JL, Wolfson MF, Castner BJ, Stocking KL, Reddy P, Srinivasan S, Nelson N, Boiani N, Schooley KA, Gerhart M, Davis R, Fitzner JN, Johnson RS, Paxton RJ, March CJ, Cerretti DP (1997) A metalloproteinase disintegrin that releases tumour-necrosis factor-alpha from cells. Nature 20:729-733

Bodmer JL, Schneider P, Tschopp J (2002) The molecular architecture of the TNF superfamily. Trends Biochem Sci 27:19-26

Bradford MM (1976) A rapid and sensitive method for the quantitation of microgram quantities of proteins utilizing the principles of protein-dye binding. Anal Biochem 72:248-254

De Leo G, Parrinello N, Di Bella MA (1987) Fine structure of blood system in Ciona intestinalis (Tunicata). Vessels and hemocytes in pharyngeal wall. Arch Biol 98:35-52

Delsuc F, Baurain D, Philippe H (2006) Origines des vertébrés: latunique fait-elle le moine? Med Sci 22:688-690

Ermak TH (1976) The hematogenic tissues of tunicates. In: Wright RK, Cooper EL (eds) Phylogeny of thymus and bone marrow-bursa cells. Elsevier/North-Holland, Amsterdam, pp 45-56

Field KG, Olsen GJ, Giovannoni SJ, Ghiselin MT, Raff EC, Pace NR, Raff RA (1988) Molecular phylogeny of the animal kingdom. Science 239:748-753

Franchini A, Miyan JA, Ottaviani E (1996) Induction of ACTH- and $\mathrm{TNF} \alpha$-like molecules in the hemocytes of Calliphora vomitoria (Insecta Diptera). Tissue Cell 5:587-592

Goetz FW, Planas JV, MacKenzie S (2004) Tumor necrosis factors. Dev Comp Immunol 28:487-497

Hori H, Osawa S (1987) Origin and evolution of organisms as deduced from $5 \mathrm{~S}$ ribosomal RNA sequences. Mol Biol Evol 5:445-472

Hughes TK, Smith EM, Chin R, Cadet P, Sinisterra J, Leung MK, Shipp MA, Scharrer B, Stefano GB (1990) Interaction of immunoactive monokines (interleukin 1 and tumor necrosis 
factor) in the bivalve mollusc Mytilus edulis. Proc Natl Acad Sci USA 87:4426-4429

Idriss TH, Naismith JH (2000) TNF alpha and the TNF receptor superfamily: structure function relationship(s). Microsc Res Tech $1: 184-195$

Käll L, Krogh A, Sonnhammer EL (2004) A combined transmembrane topology and signal peptide prediction method. J Mol Biol 14:1027-1036

Kiraga J, Mackiewicz P, Mackiewicz D, Kowalczuk M, Biecek P, Polak N, Smolarczyk K, Dudek MR, Cebrat S (2007) The relationships between the isoelectric point and length of proteins, taxonomy and ecology of organisms. BMC Genomics 12:8-163

Laemmli UK (1970) Cleavage of structural protein during the assembly of the head of bacteriophage T4. Nature 227:680-685

Le Guellec D (1998) Ultrastructural in situ hybridization: a review of technical aspects. Biol Cell 90:297-306

MacKenzie S, Planas JV, Goetz FW (2003) LPS-stimulated expression of a tumor necrosis factor-alpha mRNA in primary trout monocytes and in vitro differentiated macrophages. Dev Comp Immunol 27:393-400

Magor BG, Magor KE (2001) Evolution of effectors and receptors of innate immunity. Dev Comp Immunol 25:651-682

Mahoney R (1973) Laboratory techniques in zoology. Butterworth, London

Mazzi V (1977) Manuale di tecniche istologiche e istochimiche. Piccin, Padua

Mijatovic T, Houzet L, Defrance P, Droogmans L, Huez G, Kruys V (2000) Tumor necrosis factor-alpha mRNA remains unstable and hypoadenylated upon stimulation of macrophages by lipopolysaccharides. Eur J Biochem 267:6004-6012

Moreno E, Yan M, Basler K (2002) Evolution of TNF signaling mechanisms: JNK-dependent apoptosis triggered by Eiger, the Drosophila homolog of the TNF superfamily. Curr Biol 12:1263-1268

Nicholas KB, Nicholas Jr HB (1997) GeneDoc: analysis and visualization of genetic variation. Available from: http://www. cris.com $\sim$ ketckup/genedoc.shtml

Olivares Fontt EA, Becshin E, Van Dijck V, Vercruysse M, Bilej R, Lucas P, De Baetselier B, Vray B (2002) Trypanosoma cruzi is lysed by coelomic cytolytic factor-1, an invertebrate analogue of tumor necrosis factor, and induces phenoloxidase activity in the coelomic fluid of Eisenia foetida foetida. Dev Comp Immunol 26:27-34

Ordás MC, Costa MM, Roca FJ, López-Castejón G, Mulero V, Meseguer J, Figueras A, Novoa B (2007) Turbot TNFalpha gene: molecular characterization and biological activity of the recombinant protein. Mol Immunol 44:389-400

Ouwe-Missi-Oukem-Boyer O, Porchet E, Capron A, Dissous C (1994) Characterization of immunoreactive $\mathrm{TNF} \alpha$ molecules in the gastropod Biomphalaria glabrata. Dev Comp Immunol 18:211-218

Parrinello N (1996) Cytotoxic activity of tunicates hemocytes. In: Muller WEG, Rinkevich B (eds) Cellular, biochemical and molecular aspects of invertebrate immunology. Progress in molecular and subcellular biology. Springer, Berlin Heidelberg New York, pp 190-217

Parrinello N, Patricolo E, Canicattı C (1984a) Inflammatory-like reaction in the tunic of Ciona intestinalis (Tunicata). Encapsulation and tissue injury I. Biol Bull 167:229-237

Parrinello N, Patricolo E, Canicatt1 C (1984b) Inflammatory-like reaction in the tunic of Ciona intestinalis (Tunicata). Encapsulation tissue injury II. Biol Bull 167:238-250
Parrinello N, Arizza V, Cammarata M, Giaramita FT, Pergolizzi M, Vazzana M, Vizzini A, Parrinello D (2007) Inducible lectins with galectin properties and human IL1 $\alpha$ epitopes opsonize yeast during the inflammatory response of the ascidian Ciona intestinalis. Cell Tissue Res 329:379-390

Pfeifer K, Schröder HC, Rinkevich B, Uhlenbruck G, Hanisch FG, Kurelec B, Scholz P, Müller WE (1992) Immunological and biological identification of tumour necrosis-like factor in sponges: endotoxin that mediates necrosis formation in xenografts. Cytokine 4:161-169

Pinto MR, Chinnici CM, Kimura Y, Melillo D, Marino R, Spruce LA, De Santis R, Parrinello N, Lambris JD (2003) CiC3-1a mediated chemotaxis in the deuterostome invertebrate Ciona intestinalis (Urochordata). J Immunol 171:5521-5528

Praveen K, Evans DL, Jaso-Friedmann L (2006) Constitutive expression of tumor necrosis factor-alpha in cytotoxic cells of teleosts and its role in regulation of cell-mediated cytotoxicity. Mol Immunol 43:279-291

Rink L, Kirchner H (1996) Recent progress in the tumor necrosis factor-alpha field. Int Arch Allergy Immunol 111:199-209

Rowley AF (1981) The blood cells of the sea squirt, Ciona intestinalis: morphology, differential count, and in vitro phagocytic activity. J Invertebr Pathol 37:91-100

Schwartz R, Ting CS, King J (2001) Whole proteome pI values correlate with subcellular localizations of proteins for organisms within the three domains of life. Genome Res 11:703-709

Shida K, Terajima D, Uchino R, Ikawa S, Ikeda M, Asano K, Watanabe T, Azumi K, Nonaka M, Satou Y, Satoh N, Satake M, Kawazoe Y, Kasuya A (2003) Hemocytes of Ciona intestinalis express multiple genes involved in innate immune host defense. Biochem Biophys Res Commun 302:207-218

Silerova M, Prochazkova P, Joskova R, Josens G, Beschin A, De Baetselier P, Bilej M (2006) Comparative study of the CCFlike pattern recognition protein in different lumbricid species. Dev Comp Immunol 30:765-771

Swalla BJ, Cameron CB, Corley LS, Garey JR (2000) Urochordates are monophyletic within the deuterostomes. Syst Biol 49:52-64

Terajima D, Shida K, Takada N, Kasuya A, Rokhsar D, Satoh N, Satake M, Wang HG (2003) Identification of candidate genes encoding the core components of the cell death machinery in the Ciona intestinalis genome. Cell Death Differ 10:749-753

Thompson JD, Higgins DG, Gibson TJ (1994) Clustal W: improving the sensitivity of progressive multiple sequence alignment through sequence weighting, position-specific gap penalties and weight matrix choice. Nucleic Acids Res 22:4673-4680

Thompson JD, Gibson TJ, Plewniak F, Jeanmougin F, Higgins DG (1997) The CLUSTAL_X windows interface: flexible strategies for multiple sequence alignment aided by quality analysis tools. Nucleic Acids Res 25:4876-4882

Vizzini A, Pergolizzi M, Vazzana M, Salerno G, Di Sano C, Macaluso P, Arizza V, Parrinello D, Cammarata M, Parrinello N (2008) FACIT collagen (1alpha-chain) is expressed by hemocytes and epidermis during the inflammatory response of the ascidian Ciona intestinalis. Dev Comp Immunol 32:682-692

Wittwer D, Franchini A, Ottaviani E, Wiesner A (1999) Presence pf IL-1 and TNF-like molecules in Galleria mellonella (Lepidoptera) haemocytes and in insect cell line from Estigmene acraea (Lepidoptera). Cytokine 11:637-642

Zeng L, Swalla BJ (2005) Molecular phylogeny of the protochordates: chordate evolution. Can J Zool 83:24-33 